\title{
Balkanologie
}

Balkanologie Revue d'études pluridisciplinaires

Vol. VI, $n^{\circ}$ 1-2 | 2002

Volume VI Numéro 1-2

\section{Ada Kale}

Ada Kale

\section{Bernard Lory}

\section{(2) OpenEdition}

\section{Journals}

Édition électronique

URL : http://journals.openedition.org/balkanologie/437

DOI : $10.4000 /$ balkanologie.437

ISSN : 1965-0582

\section{Éditeur}

Association française d'études sur les Balkans (Afebalk)

\section{Édition imprimée}

Date de publication : 1 décembre 2002

Pagination : 19-22

ISSN : 1279-7952

\section{Référence électronique}

Bernard Lory, «Ada Kale », Balkanologie [En ligne], Vol. VI, n 1-2 | 2002, mis en ligne le 03 février 2009, consulté le 17 décembre 2020. URL : http://journals.openedition.org/balkanologie/437 ; DOI : https:// doi.org/10.4000/balkanologie.437

(c) Tous droits réservés 


\title{
ADA KALE
}

\author{
Bernard Lory*
}

Au milieu du XIX ${ }^{e}$ siècle, pour la plupart des Occidentaux, le "voyage en Orient" partait de Vienne. On y embarquait sur un vapeur de la Donaudampfschiffahrtsgesellschaft (Compagnie danubienne de navigation à vapeur ; le mot a longtemps été considéré comme le plus long de la langue allemande) et l'on descendait le cours du Danube. La monotonie du trajet était interrompue par le passage des Portes de Fer, où les berges abruptes et resserrées, les cataractes et le souvenir de l'empereur Trajan faisaient frissonner les touristes. Peu après Orșova et avant d'aborder la dernière cataracte, ils longeaient l'île d'Ada Kale, rencognée dans ses casemates, où d'une verdure foisonnante émergeait un minaret blanc. "C'est, pour le voyageur qui arrive de France, la première apparition de l'islamisme $n^{1}$, signale un guide touristique de l'époque.

Cette petite île de 800 mètres sur 200 occupe une position géographique particulière, à la jonction de plusieurs sous-ensembles régionaux. D'une part les Portes de fer marquent une séparation nette entre le bassin moyen du Danube, gravitant vers Vienne et Budapest, et le bassin inférieur, tourné vers la mer Noire. D'autre part, la Cerna, qui se jette dans le Danube à l'aplomb d'Ada Kale, incise l'arc carpathique et marque la limite entre le Banat de Temesvar à l'ouest et l'Olténie à l'est. Au sud, enfin, la montagne Ključ ("la Clé") isole du reste de la Serbie la Negotinska Krajina, zone de transition faisant face à la plaine de Valachie et se prolongeant, au-delà du Timok, vers le plateau bulgare.

Malgré cette position géographique intéressante, Ada Kale n'apparait que tardivement dans la grande histoire balkanique. A la fin du XVII ${ }^{\mathrm{e}}$ siècle, elle

\footnotetext{
- Maître de conférences à l'INALCO.
}

${ }^{1}$ Isambert (Emile), Orient, Grèce et Turquie d'Europe, Paris, 1873, p. 513. 
devient un enjeu important de la rivalité austro-turque pour le contröle militaire, et partant économique, du Danube. L'empereur Léopold $\mathrm{I}^{\mathrm{er}} \mathrm{y}$ fait construire les premières fortifications (sur des vestiges romains, semble-t-il) en 1689 et baptise la forteresse Neu Orsova. Le traité de Karlowitz (Sremski Karlovci) dix ans plus tard, restitue l'île aux Ottomans, qui la dénomment désormais Ada Kale, "la Forteresse de l'Ile". Les Autrichiens la réoccupent en 1718, avec le traité de Passarowitz (Požarevac) qui leur accorde la Serbie du nord et l'Olténie. A l'automne de 1738 , l'ile est reconquise par les Ottomans qui s'y réinstallent. Elle est brièvement occupée par les Autrichiens en 1791, puis restituée lors du traité de Sistovo (Svištov) la même année.

Ada Kale est le théâtre d'un épisode à la fois héroïque, sanglant et bouffon, dans la veine la plus pure de la "légende noire balkanique". Les quatre dahije, les usurpateurs qui s'étaient emparés du pachalik de Belgrade en 1801, avaient par leurs exactions poussé la population serbe à prendre les armes en février 1804. Surpris par l'insurrection, ces quatre aventuriers prirent la fuite et se réfugièrent, au mois d'août 1804 , dans la forteresse d'Ada Kale. Un commando serbe, mené par Milenko Stojković et appuyé par des forces turques loyalistes, les y rattrapa et les tua après un long combat. Leurs têtes coupées devaient ètre envoyées à Belgrade. La tâche dégoûtante de laver et d'écorcher les têtes (on exposait juste une peau séchée, bourrée de laine ou de paille) fut imposée à un malheureux Tsigane. Dans son trouble, il laissa échapper dans le fleuve une des têtes qu'on ne parvint pas à repêcher. Il fut puni de 500 coups sur la plante des pieds, peine fort lourde, mais qui lui évita de compléter le lot par sa propre tête...

Les insurgés serbes s'emparèrent bientôt de la Negotinska Krajina, mais l'île leur échappa toujours. Le commandant de la place, Receb ağa, participa à l'écrasement du mouvement insurrectionnel en 1813. Mais, suite à des intrigues, il fut exécuté sur ordre du Sultan, et ses fils se révoltèrent en 1815. Si l'exiguïté de l'île n'offrait aucune ressource, sa position géographique ouvrait aux rebelles un vaste champ d'action, en particulier en Oltenie. La Porte envoya contre eux Veli pacha, le propre fils d'Ali pacha de Janina : entre gentilshommes-brigands il ne fut pas trop difficile de trouver un terrain d'entente et les fils de Receb surent négocier leur pardon.

Plaque tournante régionale, Ada Kale fit encore parler d'elle en 1820 , lorsqu'y fut capturé un courrier compromettant entre les hétairistes de Moldavie et Miloš Obrenović. Elle fut visitée en 1835 par von Moltke et en 1862 par Kanitz qui signalèrent la décrépitude de ses fortifications. Après qu'en 1867 l'Empire ottoman eūt évacué les forteresses de Belgrade, Šabac, Smederevo et Kladovo, Ada Kale resta la position militaire turque la plus avancée sur le Danube. Elle relevait alors du gouverneur de Vidin.

La crise d'Orient et la guerre russo-turque de 1877-1878 modifièrent à nouveau le rapport de force régional. Ada Kale resta à l'écart des combats. La forte- 


\section{Vue d'Ada Kale au début du $X X^{e}$ siècle}

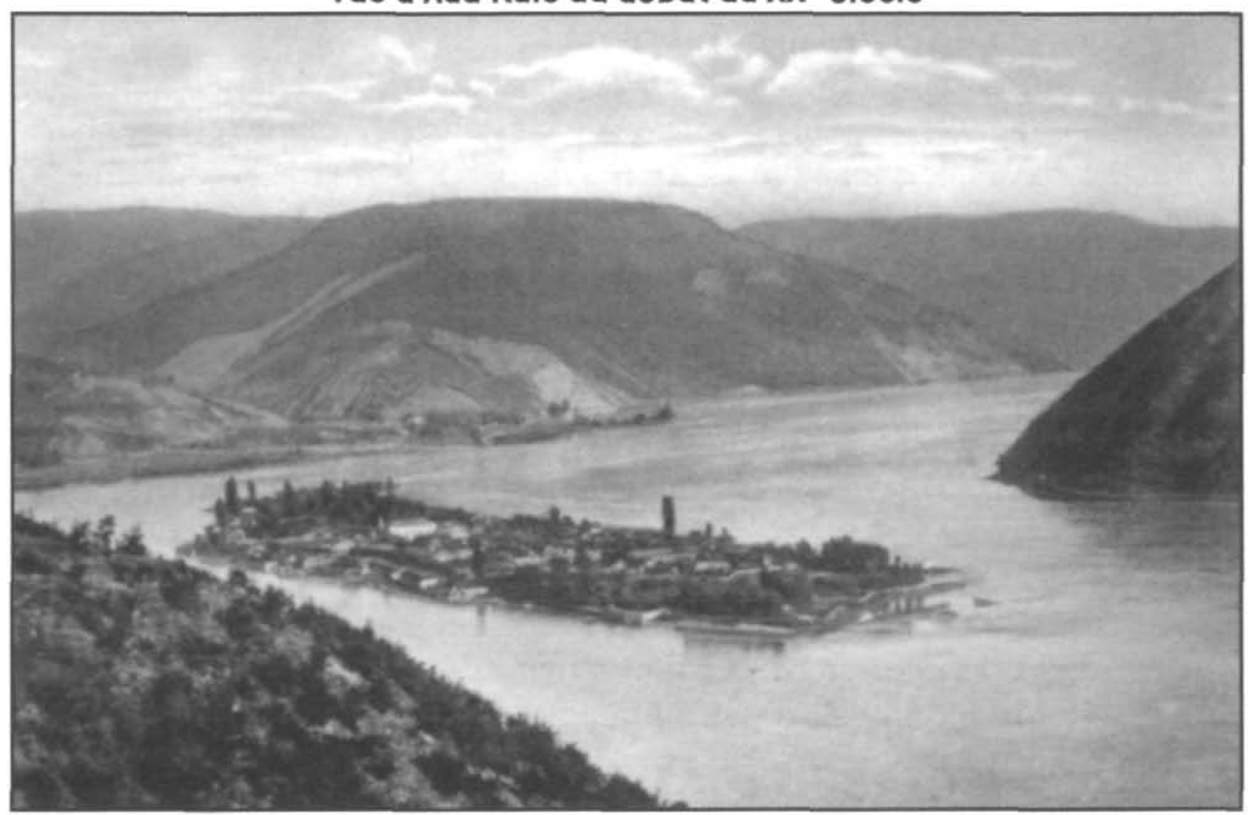

resse fut mentionnée par le Traité de San Stefano (3 mars 1878), dont l'article 3 stipulait qu'elle devait être évacuée et rasée. Cet article traitait des frontières de la Serbie, ce qui laisse entendre que l'île lui était attribuée. L'AutricheHongrie, cependant, soucieuse de son hégémonie sur la voie danubienne, s'entendit avec l'Empire ottoman et occupa préventivement Ada Kale le 26 mai 1878.

Pirouette de l'Histoire ! Le Traité de Berlin (13 juillet 1878) oublia tout simplement de mentionner Ada Kale ! Un plein mois de tractations tortueuses, de négociations d'antichambre, de bluff et de fausses promesses, de marchandages territoriaux au plus haut niveau, et la machine diplomatique laissait échapper un grain de sable, un îlot sur le grand fleuve...

Omise par l'arbitrage international, Ada Kale resta donc possession ottomane de pleine juridiction. Vidin, dont elle relevait jusqu'alors, passa à la Bulgarie, où il fut vite clair que la Porte n'avait plus grand chose à dire. Le cheflieu ottoman le plus proche était désormais Skopje...

La population de l'île, quelques centaines de Turcs (ou de musulmans balkaniques turcisés) se retrouva laissée à l'écart du grand reflux vers l'est des $m u$ hacir, qui de la fin du XVII ${ }^{e}$ à la fin du XIX ${ }^{e}$ siècle, vida de sa population musulmane tout le bassin pannonien. La langue et le folklore de ce reliquat d'une turcophonie abolie furent étudiés au début du $\mathrm{XX}^{\mathrm{e}}$ siècle par le turcologue hongrois Kúnos. Le petit minaret blanc demeurait aux avant-postes de l'Islam. 
Un nahiye müdürü représentait le pouvoir lointain du Sultan. Le petit bazar de l'île proposait café turc et pâtisseries orientales.

Ce fut un âge d'or pour l'île. Qu'on y songe : une petite communauté, soudée par la langue, la religion et le mode de vie, jouissant d'une totale exterritorialité, au point de jonction de trois frontières (hongroise, roumaine et serbe). La contrebande du tabac devint l'activité principale des habitants. Une petite fabrique de cigarettes fut ouverte, dont la production était écoulée auprès des populations riveraines.

L'anomalie internationale d'Ada Kale disparut en 1913, lorsque l'AutricheHongrie annexa la petite île. Après la Première Guerre mondiale, elle fut dévolue à la Roumanie par le Traité de Trianon (4 juin 1920). Cette décision fut cependant contestée par l'Empire ottoman, qui n'avait pas renoncé à sa souveraineté. De ce fait, il siégeait encore à la Commission internationale du Danube en 1920, comme Etat riverain. Ce n'est qu'avec le Traité de Lausanne (24 juillet 1923) que la Turquie reconnut la souveraineté rournaine sur Ada Kale.

Les Turcs d'Ada Kale vécurent donc dans le cadre de la Roumanie royale, puis communiste, comme un petit groupe marginalisé, dont les spécificités s'effritaient peu à peu du fait des mariages mixtes. Leurs compétences de contrebandiers rendirent service à de nombreux Roumains qui voulurent fuir la dictature de Gheorghiu-Dej.

Le destin étrange d'Ada Kale prit fin en 1972, avec la mise en eau du barrage des Portes de Fer, construit neuf kilomètres en aval, qui l'engloutit sous une cinquantaine de mètres d'eau. Dès 1968 la population avait été évacuée ; la petite mosquée et une partie des fortifications furent démontées et reconstruites sur l'île de Șimian, à $24 \mathrm{~km}$ en aval.

Il n'y eut pas, à proprement parler, de contentieux international à propos d'Ada Kale. Le statut juridique de l'île était sans ambiguïté et la diplomatie, prise au piège de sa propre négligence, ne trouvait à y redire. Enfin la situation géographique exceptionnelle mettait en compétition trois candidats différents (Autriche-Hongrie, Roumanie, Serbie) à cette parcelle minuscule de l'héritage ottoman. Les conflits micro-territoriaux ne mûrissent vraiment que dans des confrontations bilatérales.

\section{SOURCES UTILISÉES :}

Enciklopedija Jugoslavije, t.1, Zagreb, 1960, pp. 5-6.

Prvi srpski ustanak. Akta i pisma (La première insurrection serbe. Actes et documents), Belgrade, 1978, pp. 89-9o.

Srbija 1878, Belgrade, 1978, pp. 342-344.

Botev (Ijuben), Dojkov (Vasil), Dunav i dunavskijat voden păt (Le Danube et la voie fluviale danubienne), Sofia, 1980.

Popovic (Alexandre), L'Islam balkanique. Les musuImans du sud-est européen dans la période post-ottomane, Berlin / Wiesbaden, 1986. 